\title{
Sınıf Öğretmenlerinin Fen Öğretim Programına Yönelik Görüșlerinin Biyoloji Konuları Bakımından Değerlendirilmesi: Erzincan Örneği ${ }^{*}$
}

Evaluation of Classroom Teachers' Opinions on Science Curriculum in terms of Biology Subjects: Erzincan Sample

$$
\text { DOI =http: //dx.doi. org/10.17556/jef. } 16985
$$

$$
\text { Güntay TAŞÇi' }{ }^{* *} \text {, Meryem YILMAZ SOYLU }{ }^{* * *}
$$

\section{Özet}

$\mathrm{Bu}$ araştırmada sınıf öğretmenlerinin fen öğretim programı ile ilgili bilgi ve yeterlikleri araştırılmıştır. Çalışma, betimsel bir tarama araştırmasıdır. Çalışmanın örneklemini Erzincan Merkezdeki 17 ilkokulda görev yapan 85 öğretmen oluşturmaktadır. Veri toplama aracı olarak araştırmacılar tarafından oluşturulan bir anket formu kullanılmıştır. Veri toplama süreci 17 öğretmen adayı tarafından sınıf öğretmenleri ile yüzyüze görüşülerek yürütülmüştür. Veri analizi SPSS19 kullanılarak mod, medyan, frekans ve yüzde betimsel istatistikleri ile gerçekleştirilmiştir. Araştırma bulgularına göre sınıf öğretmenleri fen öğretim programının yapısı, uygun öğretim yöntem ve teknikleri hakkında desteklenmelidir. Ayrıca bu süreç için gerekli öğretim ortamları, materyal ve teknolojilerin onlara sağlanması gerekmektedir.

Anahtar Sözcük: fen öğretim programı, biyoloji öğretimi, sınıf öğretmeni

\begin{abstract}
This study were investigated opinions, knowledge and competencies of teachers on science curriculum. The study is a descriptive survey research. The participants were 85 elementary school teachers, which is working in 17 different primary schools in the center of Erzincan. The researchers developed a questionnaire for collecting data. Seventeen teacher candidates helped researchers for interviewing the teachers face-to-face. Descriptive statistics were used to analyze data. Analyses showed that, classroom teachers need to be supported on the structure of the curriculum and appropriate teaching methods and techniques for teaching
\end{abstract}

\footnotetext{
* Bu çalışma Topluma Hizmet Uygulamaları dersi kapsamında Erzincan İl Milli Eğitim Müdürlügü desteği ile yürütülen "Sınıfta Bilim için El Ele" adlı projeden üretilmiştir.

** Yard. Doç Dr., Erzincan Üniversitesi , gtasci@erzincan.edu.tr

*** Yard. Doç Dr., Meliksah Üniversitesi , mysoylu@meliksah.edu.tr
} 
science. Furthermore, required instructional environments with materials and technologies need to be provided for teachers. teacher

Keywords: science curriculum, biology instruction, elementary school

\section{Giriş}

Son yıllarda eğitim ve teknoloji alanlarında ortaya çıkan gelişmeler, özellikle fen eğitiminden beklentilerin değişmesine yol açmıştır. Bunun bir sonucu olarak öğrenenlerin, çağın gerektirdiği teknolojiyle baş edebilme, eleştirel düşünme gibi bir çok özelliği fen eğitimi ile kazanması gerekliliği ortaya çıkmıştır. Amerika Birleşik Devletleri Ulusal Bilim Akademisi (NRC, 1996) tarafindan oluşturulan Ulusal Fen Eğitimi Standartları, Avrupa Ülkeleri de dahil olmak üzere birçok ülkede fen öğretimine oldukça etki etmiş ve farklı ülkelerde öğretmen yetiştirme, mesleki gelişim, öğretim programlarının yeniden düzenlenmesine neden olmuştur. $\mathrm{Bu}$ değişimde, yapılan ulusal ya da uluslararası performans karşılaştırma sınavlarının sonuçları da oldukça etkili olmuştur. Bu sınavlar ile alan öğretimi ve öğretmen yeterlikleri araştırmaları önem kazanmıştır (Bingölbali, Özmantar, Sağlam, Demir, ve Bozkurt, 2012; Helmke, 2010). Bu süreçte okullardaki bilim öğretiminin bilimin doğası kapsamında yeniden ele alınmasıyla, öğretim ortamlarında bilimsel bilgi birikiminin iletilmesinden çok, bu sürecin aktif ve katılımcı bir yolla doğayı anlama çabası olarak düzenlenmesi vurgusu öne çıkmıştır (Kırıkkaya, 2009; Köseoğlu, Tümay, Altun, ve Ünlü, 2011).

$\mathrm{Bu}$ kapsamda Türkiye'de hazırlanan yeni Fen ve Biyoloji öğretim programlarının vizyonu Fen ve Teknoloji Okuryazarı bireyler yetiştirmek olarak ifade edilmektedir. Programın temel yapısını Fen Teknoloji Toplum Çevre (FTTÇ) Etkileşimi, Bilimsel Süreç Becerileri, Tutum ve Değerler olarak belirlenen kazanım alanları oluşturmaktadır (MEB, 2005; MEB, 2011). Yapılan son değişiklik ile program yapısına mevcut alanlar korunarak, yaşam becerileri, sosyobilimsel konular yeni boyutlar olarak eklenmiştir (MEB, 2013). Öğretim programı incelendiğinde fen öğretiminde, mevcut bilimsel bilgileri aktarmaktan çok bilimsel bilgi kazanma yollarına vurgu yapıldığı görülmektedir. Öğretim programında önerilen kazanım 
alanları ile öğrencilerin bilim insanlarının bilgi kazanma yollarını kullanarak bilgilere ulaşması, problem çözmesi, eleştirel düşünmesi, yaşam boyu öğrenen bireyler olarak yetişmeleri hedeflenmiştir. Bunun için tanımlanan öğretim sürecinde incelemeye dayalı öğretim stratejisinin kullanımı önerilmekte ve öğretimin gözlem, deney gibi temel inceleme yolları ile gerçekleştirilmesi istenmektedir (MEB, 2005).

$\mathrm{Bu}$ durum öğretim kalitesi ile ilişkili görülen öğretmen yeterliklerini tekrar önemli bir araştırma konusu haline getirmiştir. Literatürde öğretmen yeterlikleri öncelikle; alan bilgisi, alan öğretim bilgisi ve genel eğitim bilgisi olmak üzere üç temel boyut olarak ele alınırken, daha sonra müfredat bilgisi, öğrenenler hakkında bilgi, öğretimin bağlamına ilişkin bilgi ve öğretimin amaçlarına ilişkin bilgi olarak genişletilmiştir (Baummert ve Kunter, 2006; Nakipoğlu ve Karakoç, 2005; Park ve Oliver, 2008). Bu kapsamda öğretmen yeterlikleri ile ilgili olarak yapılan çalışmalar sonucunda MEB tarafindan genel öğretmen yeterlikleri (MEB, 2008) ve özel alan biyoloji öğretmen yeterlikleri (MEB ÖYEGM, 2011) performans göstergeleriyle yayımlanmıştır. Derin değişiklikler yapan Fen Öğretim Programının (MEB, 2005) uygulanmasında öğretmenlerin sahip olması gereken donanımlar bu çerçevede ortaya çıkarılmıştır. Bu yeterliklerin ise, öğretmenlerin öğretim programını gerçekleştirebilme gücünü yansıttığı görülmektedir.

Öğretim programının öğretmenler tarafından uygulanma düzeyi olarak tanımlanan kaliteli öğretim için yapılan değişikliklerin sınıf ortamına yansitılabilmesi gerekmektedir ki, bu da doğrudan öğretmen yeterliklerini, öğretmenlerin yeni program ile ilgili görüş, bilgi ve uygulama düzeylerini önemli araştırma konusu haline getirmektedir. Literatür incelendiğinde özellikle, bilimin doğası, bilimsel süreç becerileri, bilim ve teknoloji okur yazarlığı, öğretmen yetiştirme, öğretmenlerin mesleki gelişimleri, öğretmenlik meslek bilgisinin birçok ülkede araştırma konusu olduğu görülmektedir (Cheng vd., 2009; Delandshere ve Arens, 2001; Holins, 2011; Reinhold, 2004; Tekkaya, Çakıroğlu ve Özkan, 2004 Wray, 2007; van Dijk ve Kattmann, 2007;). Reinhold (2004) tarafindan Almanya' da reform süreci ile öğretimde değişen yaklaşım, müfredat ve yeterliklerin yansımalarına ve etkilerine dikkat çekilmektedir. Buna göre öğretmen 
eğitiminde, öğretmenlik meslek bilgisinin, belirlenen öğretmen yeterlikleri çerçevesinde işlenmesi gerektiği gösterilmektedir. Biyoloji öğretimi bakımından da öğretim kalitesi, öğretmen yeterlikleri, alana özgü öğretim kalitesi, sınıf içi iletişim sürecinin kalitesi, öğretmen yetiştirme alanlarında kapsamlı çalışmalar yürütülmektedir (Wadouh, Sandmann ve Neuhaus, 2009; Wüsten, Schmelzing, Sandmann ve Neuhaus, 2008; Wüsten vd., 2010).

Türkiye'de yapılan araştrımaların öğretim programı hakkında görüşler, program ile öne çıkan öğretim süreci değişkenlerinin etkililiği ya da uygulanma durumları ve öğretmenlerin program ile ilgili yeterlikleri üzerine odaklandıkları görülmektedir. Çavaş ve Kesercioğlu (2008) tarafından İzmir ilindeki 465 sınıf öğretmeni ile sınıf öğretmenlerinin fen ve teknoloji öğretim yeterlikleri öğretim programı temelinde hazırlanan bir ölçekle araştırılmıştır. Öte yandan ilköğretim öğretmenlerinin 2005 yılında yayımlanarak kullanılmaya başlanan Fen öğretim programı hakkında görüşlerinin de araştırıldığ görülmektedir (Bümen, 2005; Özpolat, Sezer, İşgör, ve Sezer, 2007; Kırıkkaya, 2009; Baş, 2013). Fen öğretiminde sınıf öğretmenlerinin farklı öğretim teknikleri ile ilgili sorunları, uygulama düzeyleri gibi konular da, yapılan araştırmalar arasındadır (Çam, Özkan ve Avinç, 2009; Kaptan ve Arslan, 2002; Kaya, Karaçam, Eş ve Tuncel, 2013;). Bigölbali vd. (2012) tatarafindan ise öğretim sürecinin müfredata uygun olarak gerçekleştirilebilmesi için etkinliklere odaklanılmaktadır. Diğer bir araştırma konusu öğretmenlerin öğretim programında öngörülen alternatif ölçme tekniklerini uygulamaya yönelik zorluklarının belirlenmesi olarak karşımıza çıkmaktadır (Çoruhlu, Nas, ve Çepni, 2009). MEB EARGED (2008) tarafindan yapılan sınıf öğretmenlerinin hizmet içi eğitim ihtiyaçlarının belirlenmesi çalışması ile sınıf öğretmenlerinin ihtiyaçları lisans eğitimi baz alınarak araştırılmıştır.

Fen öğretiminin ilk basamağını oluşturan üçüncü dördüncü sınıf fen dersleri, sınıf öğretmenleri tarafından verilmektedir. Bu nedenle sınıf öğretmenlerinin fen öğretim porgramını uygulayabilme düzeyleri önem kazanmaktadır. Bu çalışma, sınıf öğretmenlerinin fen öğretim programına yönelik kendileri ile ilgili algılarını ve biyoloji öğretimi açısından programın öngördüğü öğretim sürecini öğretmen görüşlerine dayalı olarak incelemeyi amaçlamaktadır. 


\section{Araștırma Soruları}

1. Sınıf öğretmenlerinin Fen Öğretim Programının temel yapısı ile ilgili bilgi düzeylerine yönelik görüşleri nasıldır?

2. Sınıf öğretmenlerinin Fen Öğretim Programının temel yapısını anlama ile ilgili destek alma düzeylerine yönelik görüşleri nasıldır?

3. Sınıf öğretmenlerinin Fen Öğretim Programında tanımlanan öğretim süreci ile ilgili bilgi düzeylerine ilişkin görüşleri nasıldır?

4. Sınıf öğretmenlerinin Fen Öğretim Programında tanımlanan öğretim sürecini uygulayabilme ile ilgili yeterlilik düzeyine ilişkin görüşleri nasıldır?

5. Sınıf öğretmenlerinin Fen Öğretim Programında tanımlanan öğretim sürecini uygulama sıklıkları nasıldır?

6. Sınıf öğretmenlerinin fen derslerinde biyoloji konularını işlerken kullandıkları öğretim yöntem ve teknikleri nelerdir?

7. Sınıf öğretmenlerinin fen öğretiminde zorlandıkları konu, kazanım ve ihtiyaç duydukları materyaller nelerdir?

\section{Yöntem}

Araştırmada betimsel tarama yöntemi kullanılmıştır.

\section{Örneklem}

Araştırmanın örneklemini Erzincan'daki 17 ilkokulda görev yapan \%47.1'i kadın, \%50.6's1 ise erkek toplam 85 sınıf öğretmeni oluşturmaktadır. Öğretmenlere ait tanımlayıcı bilgiler Tablo 1'de verilmektedir. Tablol incelendiğinde öğretmenlerin hizmet yıllarının 3 ila 36 yıl arasında değiştiği, ortalama hizmet yılının 16 yılın üzerinde olduğu, en çok birikmenin 12 yıllık öğretmenlerde olduğu görülmektedir.

Tablo 1. Örnekleme Ait Tanımlayıcı İstatistikler

\begin{tabular}{lllllll}
\hline & n & Ortalama & Min. & Maks. & Medyan & Mod \\
\hline Hizmet Yılı & 84 & 16,63 & 3,00 & 36,00 & 14,50 & 12,00 \\
Sinıf Mevcudu & 85 & 20,24 & 10,00 & 35,00 & 20,00 & 16,00 \\
Okutulan Sınıf & 85 & 2,50 & 1,00 & 4,00 & 3,00 & 4,00 \\
\hline
\end{tabular}


Öğretmenlerin sınıf mevcutlarının 10 ile 35 arasında değiştiği, ortalama 20 öğrenci ve çoğunlukla sınıf mevcudunun 16 olduğu görülmektedir. Araştırma kapsamındaki öğretmenler 1., 2., 3. ve 4. sınıfı okutmakta, çoğunlukla 4. sınıf okutan öğretmenlerden oluşmaktadır. Rasgele seçilen okullar ve öğretmenlerden oluşan örneklem bu özellikleri ile genellenebilir özellikte değildir ve yapıldığı zaman ve yer ile sinırlıdır.

\section{Veri Toplama Aract}

Araştırmanın verileri araştırmacılar tarafından geliştirilen anket formu ile toplanmıştır. Anketin geliştirilmesi için öncelikle araştırma soruları kapsamında kaynaklar incelenmiştir. $\mathrm{Bu}$ çerçevede Fen Öğretim Programı (MEB, 2005; MEB, 2013) analiz edilmiştir.

Anketin birinci bölümü örnekleme ile ilgili betimleyici bilgilere yönelik soruları içermektedir. İkinci bölümü Fen Öğretim Programının temel yapısı göz önünde bulundurularak sınıf öğretmenlerinin bilgi, uygulama yeterlikleri ve sinıfta uygulama durumlarını ölçen sorulardan oluşmaktadır. Bu sorular belirlenen her bir madde için Yetersiz (1), Orta (2), Yeterli (3); Hiç (1), Kısmen (2), Kesinlikle (3) ya da Nadir (1), Orta (2), Sık (3) şeklinde 3 derecelidir. Anketin üçüncü bölümü ise sınıf öğretmenleri tarafindan yazılarak cevaplanacak açık uçlu sorulardan oluşmaktadır. Bu sorulardan birincisi öğretmenlerin bir ders süresinin giriş, geliştirme ve sonuç bölümlerinde kullandıkları ögrretim yöntem ve tekniklerini yazmalarını içermektedir. Diğerleri ise öğretiminde zorlanılan konu, kazanım ve ihtiyaç duyulan materyal, araç-gereçlerin yazılması şeklindedir.

Anket öncelikle araştırmacılar tarafından geliştirilmiş daha sonra bir ölçme ve değerlendirme uzmanı tarafından incelenmiştir. Anket formu psikolojik bir yapıyı ölçen ya da toplam puan almaya yönelik bir özellik içermemektedir. Bu nedenle kapsam ve anlaşılırlık yönünden uzman görüşü alınarak ve pilot uygulama yapılarak ankete son hali verilmiş ve araştırmada kullanılmıştır. 
G.Taşçı, M.Y. Soylu / Ë̈ Eğitim Fakültesi Dergisi, 17(1) (2015), 55-72

\section{Veri Toplama Süreci}

Araştırma, Erzincan Üniversitesi Eğitim Fakültesi Sınıf Öğretmenliği Anabilim Dalı, 2013-2014 Eğitim ve Öğretim yılı içerisinde yürütülen Topluma Hizmet Uygulamaları dersi kapsamında, Erzincan İl Milli Eğitim Müdürlüğü ile işbirliği yapılarak yürütülmüş̧ür. Sunulan sonuçlar "Sınıfta Bilim için El Ele"projesi kapsamında toplanan verilerdir. Hazırlanan Anket formu dersi alan 17 öğretmen adayı tarafından okullardaki sınıf öğretmenlerine birebir görüşme ile uygulanmıştır.

\section{Veri Analizi}

Araştırma verileri SPSS 19 kullanılarak, nominal veri seti oluşturan sorularda mod medyan; açık uçlu sorularda ise frekans ve yüzde analizi ile çözümlenmiştir. Mod, ortalamanın hesaplanamadığı durumlarda veri hakkında kabaca bir kanı sağlayan merkezi eğilim ölçüsüdür. $\mathrm{Bu}$ değer yapılan ölçümlerde en çok tekrarlanan değeri ifade etmektedir (Büyüköztürk, Çakmak ve Köklü, 2013). Bu çalışmada öğretim programı ve öğretim süreci ile ilgili araştırma sorularına sınıf öğretmenlerinin katılma derecelerinden hangisinde birktiği mod değerine göre yorumlanmıştır.

\section{Bulgular}

$\mathrm{Bu}$ bölümde çalışma bulguları araştırma sorularına paralel olarak tablolar halinde sunulmaktadir.

\section{Sınıf Ö̆̆retmenlerinin Fen Ö̆̆retim Programı İle İlgili Bilgileri ve Yardım Alma Ihtiyacına Yönelik Görüssleri}

Sınıf öğretmenlerine Fen Öğretim Programını oluşturan ana öğeler tek tek sunularak, bunlara yönelik bilgi düzeyleri ve yardım alma durumlarına ilişkin görüşleri Tablo 2'de sunulmaktadır.

Tablo 2 incelendiğinde sınıf öğretmenlerinin fen öğretim programının yapısını oluşturan temel konular hakkındaki bilgi düzeylerinin yeterli olduğu konusunda biriktiği, ancak bu durumun 
bilimsel süreç becerileri, FTTÇ etkileşimi, Tutum Değerler ve incelemeye dayalı öğrenme konularında ortanca değerin ve yığılmanın orta düzeyde olacak şekilde değiştiği görülmektedir. Sınıf öğretmenlerinin bu konularda yardım alma ile ilgili görüşleri ise kısmen düzeyinde birikmektedir.

Tablo 2. Fen Öğretim Programına Yönelik Sınıf Öğretmenlerinin Bilgi ve Destek Almaya İlişkin Görüşleri

\begin{tabular}{|c|c|c|c|c|c|c|}
\hline & \multicolumn{3}{|c|}{ Bilgi* } & \multicolumn{3}{|c|}{ Yardım** } \\
\hline & $\mathbf{n}$ & Medyan & Mod & $\mathbf{n}$ & Medyan & Mod \\
\hline Vizyonu & 84 & 3,00 & 3,00 & 84 & 2,00 & 2,00 \\
\hline Yapısı & 85 & 3,00 & 3,00 & 83 & 2,00 & 2,00 \\
\hline Kazanımları & 84 & 3,00 & 3,00 & 82 & 2,00 & 2,00 \\
\hline Öğretim süreci & 85 & 3,00 & 3,00 & 83 & 2,00 & 2,00 \\
\hline Dil & 85 & 3,00 & 3,00 & 81 & 2,00 & 1,00 \\
\hline Ölçme Değerlendirme & 85 & 2,00 & 3,00 & 81 & 2,00 & 2,00 \\
\hline Bilimsel süreç becerileri & 84 & 2,00 & 3,00 & 82 & 2,00 & 2,00 \\
\hline FTTÇ Etkileşimi & 85 & 2,00 & 2,00 & 83 & 2,00 & 2,00 \\
\hline Tutum ve Değerler & 85 & 2,00 & 3,00 & 83 & 2,00 & 2,00 \\
\hline Bilimin Doğası & 84 & 3,00 & 3,00 & 83 & 2,00 & 2,00 \\
\hline Etkinlikler & 85 & 3,00 & 3,00 & 84 & 2,00 & 2,00 \\
\hline Alan Bilgisi & 85 & 3,00 & 3,00 & 83 & 2,00 & 2,00 \\
\hline $\begin{array}{l}\text { İncelemeye Dayalı } \\
\text { Öğrenme }\end{array}$ & 85 & 2,00 & 2,00 & 83 & 2,00 & 2,00 \\
\hline
\end{tabular}

*1:Yetersiz, 2:Orta, 3:Yeterli; **1:Hiç, 2:Kısmen, 3:Kesinlikle

Buna göre sınıf öğretmenlerinin fen öğretim programının temel yapıları ile ilgili olarak kısmen yardıma ihtiyaç duydukları söylenebilir.

\section{Sinıf Ö̆̆retmenleri Fen Öğretim Programında Tanımlanan Öğretim Süreci İle İlgili Bilgi, Yeterlik ve İstenenleri Ö̆̆retimde (Biyoloji Konuları) Kullanma Durumlarına Yönelik Görüssleri}

Sınıf öğretmenlerinin öğretim sürecinde, temel bilimsel süreç becerileri ve fen öğretimine uygun öğretim yöntemlerine ilişkin bilgi, bunları uygulamaya yönelik yeterlik ve öğretimde kullanma sıklıklarına ilişkin görüşleri Tablo 3'de verilmektedir. Sınıf öğretmenlerinin bilimsel süreç becerileri ve fen öğretimine uygun öğretim yöntem, tekniklerine yönelik bilgilerinin yeterli düzeyinde 
biriktiği görülmektedir. Bunlardan sadece okul dışı öğrenme ortamları ve modelleme ile ilgili bilgileri orta düzeyde birikmektedir. Buna karşın, öğretim sürecinde bunları uygulamaya yönelik yeterliklerine ilişkin görüş orta düzeyde birikmektedir. Öğretim sürecinde belirlenen bilimsel süreç becerilerini ve öğretim modellerini öğretimde kullanma sıklıkları ise nadir kullamada birikim göstermektedir.

Tablo 3. Sınıf Öğretmenlerinin Öğretim Sürecine İlişkin Görüşelerinin Mod ve Medyan Değerleri

\begin{tabular}{|c|c|c|c|c|c|c|c|c|c|}
\hline & \multicolumn{3}{|c|}{ Bilgi* } & \multicolumn{3}{|c|}{ Yeterlik* } & \multicolumn{3}{|c|}{ Kullanma** } \\
\hline & $\mathbf{n}$ & Medyan & Mod & $\mathbf{N}$ & Medyan & Mod & $\bar{n}$ & Medyan & Mod \\
\hline Gözlem & 85 & 3,00 & 3,00 & 76 & 2,00 & 2,00 & 85 & 1,00 & 1,00 \\
\hline Veri Kaydetme & 85 & 2,00 & 3,00 & 79 & 2,00 & 3,00 & 85 & 1,00 & 1,00 \\
\hline İletişim & 85 & 3,00 & 3,00 & 84 & 3,00 & 3,00 & 85 & 1,00 & 1,00 \\
\hline Sonuç çıkarma & 85 & 3,00 & 3,00 & 84 & 3,00 & 3,00 & 85 & 1,00 & 1,00 \\
\hline $\begin{array}{l}\text { İşbirlikli } \\
\text { Öğrenme }\end{array}$ & 84 & 3,00 & 3,00 & 84 & 2,00 & 2,00 & 85 & 1,00 & 1,00 \\
\hline Modelleme & 85 & 2,00 & 2,00 & 83 & 2,00 & 2,00 & 85 & 1,00 & 1,00 \\
\hline $\begin{array}{l}\text { Problem } \\
\text { Tabanlı } \\
\text { Öğrenme }\end{array}$ & 85 & 2,00 & 3,00 & 84 & 2,00 & 3,00 & 85 & 1,00 & 1,00 \\
\hline $\begin{array}{l}\text { Okul dışı } \\
\text { Öğrenme } \\
\text { ortamları }\end{array}$ & 83 & 2,00 & 2,00 & 84 & 2,00 & 2,00 & 84 & 1,00 & 1,00 \\
\hline Deney Yapma & 85 & 2,00 & 3,00 & 84 & 2,00 & 2,00 & 85 & 1,00 & 1,00 \\
\hline Drama & 85 & 3,00 & 3,00 & 84 & 2,00 & 2,00 & 85 & 1,00 & 1,00 \\
\hline $\begin{array}{l}\text { Oyunla } \\
\text { Öğrenme }\end{array}$ & 85 & 3,00 & 3,00 & 84 & 2,00 & 2,00 & 85 & 1,00 & 1,00 \\
\hline
\end{tabular}

*1:Yetersiz, 2:Orta, 3:Yeterli; **1:Nadir, 2:Orta, 3:S1k

Buna göre sınıf öğretmenlerinin çoğunluğunun fen öğretim programındaki yöntem ve teknikleri nadiren kullandıkları, kendilerini orta dercede uygulama yeterliğine sahip gördükleri ancak bunlar ile ilgili bilgilerini yeterli gördükleri ortaya çıkmaktadır.

\section{Sınıf Öğretmenlerinin Fen Derslerinde Biyoloji Konularını Isşlerken Kullandıkları Öğretim Yöntem ve Teknikleri}

Sınıf öğretmenlerinin fen derslerinde biyoloji konularını işlerken dersin giriş, geliştirme ve sonuç bölümlerinde kullandıkları öğretim yöntem ve tekniklerinin frekansları ve oranları Tablo 4'te verilmektedir. Buna göre sinıf öğretmenlerinin fen derslerinde biyoloji konularının öğretiminde en yüksek oranda soru cevap (\%16,5; \%23,5; $\% 25,9)$ tekniğini kullandıkları görülmektedir. Dersin giriş aşamasında 
dikkat çekme etkinliği öğretmenlerin \%13,7'si tarafından kullanılmaktadır. Beyin firtınası, önbilgi yoklama, örnek olay ve anlatım yöntem ve tekniklerinin kullanımı ise sınıf öğretmenlerinin \%10'undan daha azı tarafından bildirilmektedir. Sınıf öğretmenlerinin \%3'ünden daha azı tarafindan bidirilen teknikler ise diğer olarak ele alınmış bunların drama, eğitsel oyun olduğu görülmüştür. Sınıf öğretmenlerinin yarısına yakını dersin geliştirme bölümünde anlatım $(\% 27,1)$ ve soru cevap $(\% 23,5)$ tekniklerini kullanmaktadır.

Tablo 4. Sınıf Öğretmenlerinin Ders Tasarımlarındaki Yöntem ve Tekniklerin Yüzde ve Frekansları

\begin{tabular}{|c|c|c|c|c|c|c|c|c|}
\hline \multicolumn{3}{|c|}{ GİRİŞ } & \multicolumn{3}{|c|}{ GELİŞTİRME } & \multicolumn{3}{|c|}{ SONUÇ } \\
\hline & $\mathbf{F}$ & $\%$ & & $\mathbf{f}$ & $\%$ & & $\mathbf{f}$ & $\%$ \\
\hline Soru cevap & 14 & 16,5 & Anlatım & 23 & 27,1 & Soru cevap & 22 & 25,9 \\
\hline $\begin{array}{l}\text { Dikkat } \\
\text { Çekme }\end{array}$ & 12 & 14,1 & Soru cevap & 20 & 23,5 & Anlatım & 8 & 9,4 \\
\hline $\begin{array}{l}\text { Beyin } \\
\text { furtınası }\end{array}$ & 8 & 9,4 & Deney & 12 & 14,1 & Özet & 4 & 4,7 \\
\hline $\begin{array}{l}\text { Ön bilgi } \\
\text { yoklama }\end{array}$ & 6 & 7,1 & $\begin{array}{l}\text { Beyin } \\
\text { firtınası }\end{array}$ & 10 & 11,8 & Örneklendirme & 3 & 3,5 \\
\hline Örnek olay & 6 & 7,1 & Tartışma & 7 & 8,2 & Eğitsel oyunlar & 2 & 2,4 \\
\hline Anlatım & 7 & 8,2 & Örnekleme & 4 & 4,7 & Beyin firtınası & 1 & 1,2 \\
\hline Öyküleme & 2 & 2,4 & Drama & 3 & 3,5 & Deney & 1 & 1,2 \\
\hline Drama & 1 & 1,2 & $\begin{array}{l}\text { Eğitsel } \\
\text { oyun }\end{array}$ & 2 & 2,4 & Drama & 1 & 1,2 \\
\hline Rol oynama & 1 & 1,2 & Gösteri & 2 & 2,4 & Tartışma & 1 & 1,2 \\
\hline Diğger* & 7 & 8,2 & Diğer** & 2 & 2,4 & Diğer*** & 9 & 10,6 \\
\hline Boş & 21 & 24,7 & & & & Boş & 33 & 38,8 \\
\hline Toplam & 85 & 100 & Toplam & 85 & 100 & Toplam & 85 & 100 \\
\hline
\end{tabular}

* motivasyon, klavuz kitaba bağlı kalıyorum, görsel ve işitsel araçlar, görsel sunu, derse hazırlık, çevreden ve geçmiş yaşantılar

** okuma-anlama, konuyu okutma ve özetleme

*** dönüt, yaparak yaşayarak öğrenme, ev ödevi, gözlem, verileri yorumlama, sonuç çıkarma

Deney, beyin firtınası ve tartışma teknikleri ise \%14 ile \%8,3 arasında değişmektedir. Dersin sonuç bölümünde ağırlıklı olarak soru cevap tekniği ve anlatım kullanıldığ 1 ifade edilmektedir. Tablo 4'te öne çıkan diğer bir bulgu ise sınıf öğretmenlerinin \%25'i girşte, \%39'u ise sonuç bölümünde yöntem ve teknik belirtmemiştir. Buna göre sinıf öğretmenlerinin biyoloji konularının öğretiminde ders tasarımlarının ağırlıklı olarak anlatım ve soru cevap teknikleri üzerine yoğunlaştığı 
söylenebilir. $\mathrm{Bu}$ durum sınıf öğretmenlerinin öğretim süreçlerinde yöntem çeşitliliğinin olmadığını ya da ders süresinin bölümlerine uygun yöntem ve teknikleri entegre edemediğini göstermektedir.

\section{Sınıf Ö̆̆retmenlerinin Fen Ö̆̆retiminde Zorlandıkları Konu, Kazanım ve İhtiyaç Duydukları Materyaller}

Sınıf öğretmenlerinin fen derslerinde öğretmekte zorlandıkları konular ve kazanımlar Tablo 5 ve Tablo 6'da verilmektedir. Tablo 5 incelendiğinde sınıf öğretmenlerinin büyük çoğunluğunun (\%75) kazanım belirtmediği, belirtilen kazanımların genel ifadeler ile yazıldıkları görülmektedir. Yazılan kazanımların belirtilen konular ile uyumlu olduğu görülmektedir.

Tablo 5. Sınıf Öğretmenlerinin Fen Öğretinminde Zorlandıkları Kazanımların Yüzde ve Frekansları

\begin{tabular}{llc}
\hline & f & \% \\
\hline Bir varlığın canlı ve cansız olduklarını sorgulayarak karar verir. & 1 & 1,2 \\
Destek ve hareket ünitesi kazanımları & 1 & 1,2 \\
$\begin{array}{l}\text { Dünya'nın yapısında bulunan maddelerin önemi hakkında bilgi } \\
\text { edinmesi. }\end{array}$ & 1 & 1,2 \\
Gözlem gerektiren kazanımlar & 1 & 1,2 \\
Isının madde üzerindeki etkileri ve karışımlar, çözeltiler konusundaki & 1 & 1,2 \\
kazanımlarda & & 1,2 \\
Işık, ses ile ilgili kazanımlar. & 1 & 1,2 \\
Kasların lifli yapısı sayesinde kasılıp gevşediği ve kemikleri harekete & 1 & \\
geçirdiğini açıklar & & 1,2 \\
Kuvvetin cisimlerin hareket ve şekilleri üzerinde ki etkilerini açılama & 1 & 1 \\
Saf madde ve karışım arasındaki farkları açıklar & 1 & 1,2 \\
Sebeb sonuç ilişkisi kurma & 1 & 1,2 \\
Uyku halindeki canlı varlıkların uygun koşullar oluştuğunda canlılık & & \\
özelliği çıkarımını yapar. & 1 & 1,2 \\
Varlıkların haraket özelliklerini karşılaştırarak sınıflandırır. & 1 & 1,2 \\
Varlıkların sınıflandırılması belirsizlik olabileceğinin farkına varır & 2 & 2,4 \\
Elektrik devreleri konusu kazanımlar & 64 & 75,3 \\
Kazanım Bildirmeyenler & &
\end{tabular}

Bununla birlikte Tablo 6 incelendiğinde öğretmenlerin \%28'i hiçbir konu belirtmemektedir. Öğretiminde zorlanıldığı bildirilen konular arasında vücudumuzu tanıyalım ve deney yaptırılması gereken 
konuların en yüksek orana sahip oldukları, Canlılar Dünyası, Mikroskobik Canlılar, Canlıların Ortak Özellikleri konularının ise daha düşük oranda oldukları belirlenmiştir.

Tablo 6. Sınıf Öğretmenlerinin Fen Öğretinminde Zorlandıkları Konuların Yüzde ve Frekansları

\begin{tabular}{lll}
\hline & f & \% \\
\hline Konu Bildirmeyenler & 24 & 28,24 \\
Vücudumuzu Tanıyalım & 10 & 11,76 \\
Deney Yaptırmam Gereken Konular & 10 & 11,76 \\
Madde & 9 & 10,59 \\
Elektrik & 8 & 9,41 \\
Işık ve Ses & 7 & 8,24 \\
Canlılar Dünyası & 4 & 4,71 \\
Dünya Uzay Gezegen & 4 & 4,71 \\
Mikroskobik Canlılar & 3 & 3,53 \\
Isı ve Sıcaklık & 2 & 2,35 \\
Kuvvet ve Hareket & 2 & 2,35 \\
Canlıların Ortak Özellikleri & 1 & 1,18 \\
Toplam & 85 & 100,00 \\
\hline
\end{tabular}

Tablo 7 incelendiğinde sinıf öğretmenlerinin \%36,47'sinin laboratuvar ve deney malzemelerinin eksikliğini bildirdikleri görülmektedir. Hemen bunun ardından ise özellikle biyoloji öğretiminde önemli olan mikroskop ve modeller ihtiyaç duyulan araçlar arasında görülmektedir.

Tablo 7. Sınıf Öğretmenlerinin Fen Öğretinminde İhtiyaç Duydukları Materyallerin Yüzde ve Frekansları

\begin{tabular}{lll}
\hline & f & $\mathbf{\%}$ \\
\hline Laboratuvar, Deney Araç Ve Gereçleri & 31 & 36,47 \\
Mikroskop, Lam, Lamel & 11 & 12,94 \\
Model & 11 & 12,94 \\
Projeksiyon Ve Bilgisayar & 8 & 9,41 \\
Akıllı Tahta & 7 & 8,24 \\
Elektirik Devresi & 4 & 4,71 \\
Poster & 2 & 2,35 \\
Değişik Taş Örnekleri & 1 & 1,18 \\
İhtiyaç Bildirmeyenler & 10 & 11,76 \\
Toplam & 85 & 100 \\
\hline
\end{tabular}


G.Taşçı, M.Y. Soylu / EÜ Ĕ̆itim Fakültesi Dergisi, 17(1) (2015), 55-72

Modeller özellikle çiçek modeli, iskelet modeli olarak örneklenmektedir.

\section{Sonuç ve Tartışma}

Araştırma bulgularına göre Fen Öğretim Programında önerilen öğretim süreci ile ilgili bilimsel süreç becerileri ve öğretim yöntemleri sınıf öğretmenleri tarafından nadiren kullanılmaktadır. Sınıf öğretmenleri bu yöntemler ve bilimsel süreç becerilerini öğretimde uygulayabilme hakkında ise kendilerini orta düzeyde yeterli görmektedir. Sınıf öğretmenlerinin ders tasarımları ile ilgili bulguda bu veriyle uyumlu olarak sınıf öğretmenlerinin fen derslerinde genellikle anlatım, soru cevap tekniklerini kullandıkları görülmektedir. Çavaş ve Kesercioğlu (2008) tarafından yapılan çalışmada sınıf öğretmenlerinin fen öğretmen yeterlikleri bakımından zayıf oldukları konusunda literatür aktarılmaktadır. Baş (2013) tarafından yapılan çalışma bulgularında da öğretmenlerin fen öğretim programının öğretim sürecine ilişkin yeterlik görüşlerinin düşük olduğu belirlenirken, sınıf öğretmenlerinin fen öğretim programı hakkında bilgi eksiklikleri ile ilgili literatüre dikkat çekilmektedir. Bulut (2008) tarafından yapılan çalışmada ise öğretmenlerin öğretim programını öğrenci merkezli olarak orta düzeyde uyguladıkları bildirilmektedir. Ayrıca sınıf öğretmenleri 3-4. Sınıf Fen Öğretim Programı ile ilgili kısmen desteğe ihtiyaç duymaktadır. 2005 yılından beri uygulamada olan ve öncesine göre köklü değişimler getiren fen öğretim programı teorik temelleri ile birlikte, öğretim sürecinde de bir çok değişimi birlikte getirmiştir. Literatürde yapılan çalışmalara bakıldığında bu bulgu ile uyumlu olarak sınıf öğretmenlerinin öğretim programı ile ilgili ölçme değerlendirme de dahil olmak üzere desteğe ihtiyaç duydukları yönünde çalışma sonuçlarına rastlanmaktadır (Baş, 2013; Çoruhlu, Nas ve Çepni, 2009; Kırıkkaya, 2009).

Literatürde yapılmış çalışmalardan farklı olarak bu çalışma ile ortaya koyulan sınıf öğretmenlerinin fen derslerinde biyoloji konularının ögrretiminde ağırlıklı olarak anlatım, soru cevap tekniği kullandıkları ve öğretmenler tarafindan öğretiminde zorlanılan konu ve kazanımlarda biyoloji alanının yüksek oranlarda olduklarıdır. Sınıf öğretmenlerinin ihtiyaç duyudukları materyal ve araçların başında laboratuvar ve özellikle mikroskop, modellerin gelmesi diğer önemli bir sonuçtur. Öğretiminde zorlanılan konular, kazanımlar ile uyumlu olan bu eksiklikler öğretim sürecinin, fen öğretim programındaki gibi yürütülememesinde diğer önemli bir etken olarak karşımıza çıkmaktadır. Yapılan farklı çalışmalarda da öğretim sürecinin programın öngördüğü şekilde yürütülememesinde öğretim ortamları ve materyal araç gereç eksiklikleri önemli bir etken olarak 
bildirilmektedir (Baş, 2013; Şengül, Çetin ve Gür, 2008). Ortaöğretim düzeyinde yapılan diğer araştırmalarda biyoloji öğretiminde öğretmenlerin laboratuvar uygulamaları, modeller ve diğer yöntemlerin biyoloji öğretiminde kullanılması konusunda olumlu görüşleri olduğu ancak daha çok anlatım soru cevap tekniklerinin kullanıldığı bildilirilmektedir (Atıcı, ve Bora, 2004; Gürbüz, ve Sülün, 2004; Temelli ve Kurt, 2011). Bu sonuçlara paralel olarak MEB EARGED (2008) tarafından yapılan çalışmaya göre Türkiye'deki sınıf öğretmenlerinin \%80' i Fen ve Teknoloji Laboratuvarı Uygulamaları, \% 52'si ise Genel Biyoloji ile ilgili hizmet içi eğitime ihtiyaçlarının olduğunu bildirmektedir.

Yapılan çalışma sonuçları kendi içlerinde ve incelenen literatür ile uyumlu olarak sınıf öğretmenlerinin biyoloji öğretimini fen öğretim programı çerçevesinde gerçekleştirebilmesi için birçok bakımdan desteklenmesi gerektiğini ortaya çıkarmaktadır. Bunların, öğretim programına yönelik bilgilendirme, öğretim süreci gereklilikleri olarak bilimsel süreç becerileri ve öğretim yöntem teknikleri, materyal araç ve gereçlerin sağlanması, sınıf ya da ilkokul binalarına fen öğretimine özgü laboratuvar ortamı oluşturulması olarak sıralanması mümkündür.

\section{Kaynaklar}

Atıcı,T. \& Bora, N. (2004). Orta Öğretim Kurumlarında Biyoloji Eğitiminde Kullanılan Öğretim Metotlarının Ders Öğretmenleri Açısından Değerlendirilmesi Ve Öneriler. Afyon Kocatepe Üniversitesi Sosyal Bilimler Enstitüsü Dergisi , Cilt 6(2).

Baş, G. (2013). 2005 İlköğretim Programları Hakkında Öğretmen Görüşleri. Erzincan Üniversitesi Eğitim Fakültesi Dergisi, 67-95.

Baumert, J. \& Kunter, M. (2006). Stichwort: Professionelle Kompetenz Von Lehrkräften. Zeitschrift Für Erziehungswissenschaft , cilt 9(4), 469-520.

Bingölbali, E., Özmantar, M. F., Sağlam, Y., Demir, S., \& Bozkurt, A. (2012). İlköğretim Ögretmenlerinin Fen Ve Matematik Alanlarinda Mesleki Gelişim Modeli Ve Bu Modelin Yayginlaştirilmasi. Gaziantep: TÜBİTAK.

Bulut , İ. (2008). Yeni_lkögretim Programlarında Öngörülen Ögrenci Merkezli Uygulamalara _liskin Ögretmen Görüsleri (Diyarbakır_li Örnegi. Kuram ve Uygulamada Eḡitim Yönetimi, 521-546.

Bümen, T. (2005). Öğretmenlerin Yeni İlköğretim 1-5 Sıf Programları ile ilgili Görüşleri Ve Programı Uygulamaya Hazırlayıcı Bir Hizmet İçi Eğitim Çalışması Örneği. Ege Eğitim Dergisi, 21-57.

Cheng, M., Chan, K.W., Sylvia Y.F., Tang, Annie, \& Cheng, Y.N. (2009). Pre-Service Teacher Education Students' Epistemological Beliefs And Their Conceptions of Teaching . Teaching And Teacher Education , 25, s. 319-327.

Çam, F., Özkan , E., \& Avinç, İ. (2009). Fen ve Teknoloji Dersinde Drama Yönteminin Akademik Basarı ve Derse Karsı İlgi Açısından Karsılastırmalı Olarak İncelenmesi: Köy ve Merkez Okulları Örnegi. Gazi Egitim Fakültesi Dergisi,, 29(2), 459-483.

Çavaş, H. P., \& Kesercioğlu, T. (2008). Sınıf Öğretmenlerinin Fen Ve Teknoloji Öğ-retim Yeterliklerinin Belirlenmesi. Ege Eğitim Dergisi, 9(1), 75-94. 
G.Taşçı, M.Y. Soylu / EÜ Eğitim Fakültesi Dergisi, 17(1) (2015), 55-72

Çoruhlu, T., Nas, , S., \& Çepni, S. (2009). Fen Ve Teknoloji Öğretmenlerinin Alternatif Ölçmedeğerlendirme Tekniklerini Kullanmada Karşılaştıkları Problemler: Trabzon Örneği. Yüzüncü Yıl Üniversitesi, Eğitim Fakültesi Dergis, 122-141.

Delandshere, G., \& Arens, S. A. (2011). Representations Of Teaching And Standards-Based Reform: Are We Closing The Debate About Teacher Education. Teaching And Teacher Education , 17, s. 547-566.

Gürbüz, H., \& Sülün, A. (2004). Türkiye' de Biyoloji Öğretmenleri Ve Biyoloji Öğretmen Adaylarının Nitelikleri. Milli Ĕgitim Dergisi, Sayı 161.

Helmke, A. (2010). Unterrichtsqualität. (Edit)Detlef Rost. Handwörterbuch Paedagogische Psychologie 4. Auflage. Beltz Pvu, (s. 886-895).

Holins, R. (2011). Teacher Preparation For Quality Teaching . Journal Of Teacher Education, 62, s. 395.

Kaptan, F., \& Arslan, B. (2002). Fen Öğretiminde Soru-Cevap Tekniği İle Analoji Tekniğinin Karşılaştırılması. old.fedu.metu.edu.tr: http://old.fedu.metu.edu.tr/ufbmek5/b_kitabi/PDF/Fen/Poster/t48d.pdf adresinden alınmıştır

Kaya, S., Karaçam, S., Eş, H., \& Tuncel, M. (2013). 4. ve 5. Sınıf Öğretmenlerinin Fen ve Teknoloji Dersinde Proje ve Performans Görevlerine İlişkin Görüşleri. Pamukkale Üniversitesi Eğitim Fakültesi Dergisi, 187-201.

Kırıkkaya, E. B. (2009). İlköğretim Okullarındaki Fen Öğretmenlerinin Fen Ve Teknoloji Programına İlişskin Görüşleri. Türk Fen Eğitimi Dergisi, 133-148.

Köseoğlu, F., Tümay, H., Altun, Y., \& Ünlü, P. (2011). Bilimin Doğası Öğretimi: Bilim Felsefesi ve Bilim Tarihine Dayanarak Bilimsel Argüman Oluşturma ve Akıl Yürütme Öğretimine Yönelik Bir Öğretmen Mesleki Gelişim Paketinin Hazırlanması. ANKARA: TÜBİTAK(108K086).

MEB. (2005). Talim Ve Terbiye Kurulu Başkanlı̆̆ı . Fen Ve Teknoloji Dersi(4-5.Sınıflar) ÖğretimProgram1.:http://ttkb.meb.gov.tr/program2.aspx/program2.aspx?islem=1\&k no $=25$ adresinden alınmıştır

MEB. (2011). Ortaöğretim Biyoloji Dersi Öğretim Programı. Talim Ve Terbiye Kurulu: http://ttkb.meb.gov.tr/program2.aspx/program2.aspx?islem=1\&kno=162 adresinden alınmıştır

MEB Öğretmen Yetiştirme Ve Eğitimi Genel Müdürlüğü. (2008). Öğretmenlik Mesleği Genel Yeterlikleri. . www.otmg.meb.gov.tr: http://otmg.meb.gov.tr/belgeler/ogretmen_ yeterlikleri_kitabi/\%c3\%96\%c4\%9fretmen_yeterlikleri_adresinden alınmıştır

MEB. (2011). Özel Alan Yeterlikleri Biyoloji. $0 \overline{3}$ 22, 2013 tarihinde www.otmg.meb.gov.tr:http://otmg.meb.gov.tr/yeterlikdos/b\%c4\%b0yoloj\%c4\%b0/ b\%c4\%b0yoloj\%c4\% b0.pdf adresinden alındı

Nakiboğlu, C., \& Karakoç, Ö. (2005). Öğretmenin Sahip Olması Gereken Dördüncü Bilgi: Alan Öğretimi. Kuram ve Uygulamada Eğitim Bilimleri, 5(1), 181-206.

NRC. (1996). National Science Education Standards. Washington, Dc: National Academy Press.

Özpolat, A., Sezer, F., İşgör, İ. Y., \& Sezer, M. (2007). Sinif Öğretmenlerinin Yeni İlköğretim Programina İlişkin Görüşlerinin İncelenmesi. Millî Ĕgitim Dergisi(174), 206-211.

Park, S. \& Oliver, J.S. (2008). Revisiting The Conceptualisation Of Pedagogical Content Knowledge (Pck): Pck As A Conceptual Tool to Understand Teachers As Professionals. Research Of Science Education , 38, 261-284.

Reinhold, P. (2004). Naturwissenschaftsdidaktische Forschung İn Der Lehrerausbildung. Zeitschrift Für Didaktik Der Naturwissenschaften, 10, 117-145.

Şengül, H., Çetin, G., \& Gür, H. (2008). The Primary School Science Teachers’ Problems in Science. Türk fen eğitimi dergisi, 5(3), 82-88. 
Tekkaya, C., Çakıroğlu, J., \& Özkan, O. (2004). Turkish Pre-Service Science Teachers' Understanding Of Science And Their Confidence İn Teaching İt. Journal Of Education For Teaching: International Research And Pedagogy, 30(1), 57-68.

Temelli, A., \& Kurt, M. (2011). Biyoloji Öğretmenlerinin Kullandıkları Öğretim Yöntemleri $\mathrm{Ve} \mathrm{Bu}$ Yöntemlerin Öğrenci Başarısına Etkileri Hakkındaki Görüşler. EInternational Journal Of Educational Research , 2(2), 65-76.

Van Dijka, E. M., \& Kattmann, U. (2007). A Research Model For The Study Of Science Teachers' Pck And İmproving Teacher Education. Teaching And Teacher Education , 23, 885-897.

Wadouh, J., Sandmann, A., \& Neuhaus, B. (2009). Interconnecting Subject Matter İn Biology Lessons - Descriptive Results Of A Video Study. Zeitschrift Für Didaktik Der Naturwissenschaften, 15, 69-87.

Wray, S. (2007). Teaching Portfolios, Community, And Pre-Service Teachers' Professional Development. Teaching And Teacher Education, 23, 1139-1152.

Wuttke, E. (2005). Unterrichtskommunikation Und Wissenserwerb. Zum Einfluss Von Kommunikation Auf Den Prozess Der Wissensgenerierung. Peter Lang, Frankfurt am Main, 55-86.

Wüsten, S., S. Schmelzing, A. Sandmann ve B. Neuhaus. (2010). Sachstrukturdiagramme Eine Methode Zur Erfassung İnhaltsspezifischer Merkmale Der Unterrichtsqualität İm Biologieutnerricht. Zeitschrift Für Didaktik Der Naturwissenschaften, 16, 7-23.

Wüsten, S., Schmelzing, , S., Sandmann , A., \& Neuhaus,, B. (2008). Unterrichtsqualitätsmerkmale İm Fach Biologie. D. A. Krüger içinde, Erkenntnisweg Biologiedidaktik 7 (s. 145-158). Hannover.

\section{Extended Summary}

\section{Purpose}

In this study, elementary school teachers' opinions, knowledge and competencies regarding science curriculum were investigated.The researchers pursued problems below:

\section{Research Questions}

1. What were the opinions of the teachers on their level of knowledge regarding the basic structure of Science Curriculum?

2. What were the opinions of the teachers on their level of getting support for understanding the basic structure of Science Curriculum?

3. What were the opinions of the teachers on their level of knowledge regarding the teaching process defined in the Science Curriculum?

4. What were the opinions of the teachers on their level of implementing teaching plans defined in the Science Curriculum?

5. How often did the teachers implement the teaching plans defined in the Science Curriculum? 
6. Which teaching methods and techniques did the teachers use while teaching biology in science classes?

7. What chapter, goal did the teachers have difficulty and what kind of materials do they need to teach?

\section{Method}

The research was a descriptive survey research. The sample consisted of 85 elementary school teachers working in 17 different elementary schools in the center of Erzincan. It was observed that the range of teachers' service was between 3 and 36 years, average years of the service was above 16 years and mod of the service was 12-years. They were 1st, 2nd, 3rd and 4th grade teachers, and most of them were teaching 4th grade. The researchers were developed a questionnaire to collect data. The questionnaire included threelevel categorical and open-ended questions prepared according to Science Curriculum. Seventeen teacher candidates were helped researchers to interview the teachers face-to-face. Data analysis was done using SPSS19 with descriptive statistics mode, median, frequencies and percentages.

\section{Results}

The opinions of elementary teachers on their level of knowledge regarding the Science Curriculum was found to be "adequate", however, their need for support in this regard was "partially" adequate (Table 2).

The majority of classroom teachers think that they have an adequate level of knowledge about science process skills as well as appropriate teaching methods and techniques in science teaching. These teachers exceptionally thought that they had a moderate-level of knowledge regarding the out-school learning environments and modeling. Regarding competencies to implement them in the teaching processteachers reported moderate competency level. However the frequency of using science process skills and teaching models identified in the teaching process was very low (Table. 3).

The teachers mostly chose question and answer technique (\%16,5; $\% 23,5 ; \% 25,9)$ in the course's introduction, development and results sections during the biology-related subjects of the science classes. Less than $10 \%$ of the teachers, however, preferred the brainstorming, prior knowledge activation methods during introduction phase of the class. Almost half of the the teachers employed verbal presentation (27,1\%), question and answer (23,5\%) during the course's development phase. At this stage; experiment, brainstorming and discussions were employed fewer than 14\% (Table 4). 
"Let's learn about our bodies" chapter and any chapter that required experiements were reported the most difficult sections to teach. (Table 5). In Table 7, however, it was seen that $37.2 \%$ of the teachers reported the lack of laboratory and experimental materials. Afterwards, the teachers also pointed out need of microscopes and models for biology teaching.

\section{Discussion and Conclusion}

The results of the study showed that the teachers must be supported in many ways in order to perform biology teaching in the context of science curriculum. Some of the support may include informing them about the curriculum, scientific process skills and teaching methods as teaching process requirements, provision of material, tools and equipment and/or establishing a laboratory specific to science teaching in classrooms or school. Unlike other studies in the literature this study revealed that the teachers mainly used oral presentations and question and answer methods while teaching biology in the science classes. In addition, the teachers reported biology as the most complex and difficult to teach features of the science curriculum. In conclusion, providing practical training to teachers in order to enable them to meet the requirements of the curriculum would be useful. 